\title{
A comparison of measurement methods: terrestrial laser scanning, tachymetry and snow probing for the determination of the spatial snow-depth distribution on slopes
}

\author{
A. PROKOP, ${ }^{1,2}$ M. SCHIRMER, ${ }^{2}$ M. RUB, ${ }^{3}$ M. LEHNING, ${ }^{2}$ M. STOCKER ${ }^{3}$ \\ ${ }^{1}$ Institute of Mountain Risk Engineering, Department of Civil Engineering and Natural Hazards, BOKU - University of Natural \\ Resources and Applied Life Sciences, Peter Jordan Strasse 82, A-1180 Vienna, Austria \\ E-mail: alexander.prokop@boku.ac.at \\ ${ }^{2}$ WSL Swiss Federal Institute for Snow and Avalanche Research SLF, Flüelastrasse 11, CH-7260 Davos-Dorf, Switzerland \\ ${ }^{3}$ Institute of Geodesy and Photogrammetry, ETH Hoenggerberg, CH-8093 Zürich, Switzerland
}

\begin{abstract}
Determination of the spatial snow-depth distribution is important in potential avalanchestarting zones, both for avalanche prediction and for the dimensioning of permanent protection measures. Knowledge of the spatial distribution of snow is needed in order to validate snow depths computed from snowpack and snowdrift models. The inaccessibility of alpine terrain and the acute danger of avalanches complicate snow-depth measurements (e.g. when probes are used), so the possibility of measuring the snowpack using terrestrial laser scanning (TLS) was tested. The results obtained were compared to those of tachymetry and manual snow probing. Laser measurements were taken using the long-range laser profile measuring system Riegl LPM-i800HA. The wavelength used by the laser was $0.9 \mu \mathrm{m}$ (near-infrared). The accuracy was typically within $30 \mathrm{~mm}$. The highest point resolution was $30 \mathrm{~mm}$ when measured from a distance of $100 \mathrm{~m}$. Tachymetry measurements were carried out using Leica TCRP1201 systems. Snowpack depths measured by the tachymeter were also used. The datasets captured by tachymetry were used as reference models to compare the three different methods (TLS, tachymetry and snow probing). This is the first time that the accuracy of TLS systems in snowy and alpine weather conditions has been quantified. The relative accuracy between the three measurement methods is bounded by a maximum offset of $\pm 8 \mathrm{~cm}$. Between TLS and the tachymeter the standard deviation is $1 \sigma=2 \mathrm{~cm}$, and between manual probing and TLS it is up to $1 \sigma=10 \mathrm{~cm}$, for maximum distances for the TLS and tachymeter of $300 \mathrm{~m}$.
\end{abstract}

\section{INTRODUCTION}

Measuring the spatial snow-depth distribution and the snowpack volume in alpine conditions is a fundamental problem not only for avalanche research but also for glaciological and snow hydrology research. Exhaustive field inspections of snow depth using snow probes are timeconsuming and not always feasible.

Consequently, remote-sensing techniques have been used (e.g. validation of snow transport models with terrestrial photogrammetry (Corripio and others, 2004); measurement of snow depth to estimate snow water equivalence from aerial frequency-modulated continuous wave (FM-CW) radar (Yankielun and others, 2004); determination of snowcovered area from satellite data (Rosenthal and Dozier, 1996); and assessment of the mass balance of snow avalanches (Sovilla and others, 2006)). The use of airborne laser scanning for snow-depth measurements beneath a variable forest canopy has also been evaluated (Hopkinson and others, 2001). However, a validated and reliable remote sensing of the snow-depth distribution at a high spatial resolution has not yet been attained. Terrestrial laser scanning (TLS) methodology was chosen to fulfil the accuracy requirements of potential avalanche-starting zones, where a $30 \mathrm{~cm}$ difference in snow depth is critical for triggering avalanches. Most of the available terrestrial laser scanners measure ranges to objects of up to several hundred metres, with a single-point accuracy of $1 \sigma=1.4-$ $15 \mathrm{~mm}$ at $50 \mathrm{~m}$ (Ingensand, 2006). Detailed investigations of TLS accuracy (Boehler and Marbs, 2002) and comparison with digital photogrammetry (Lichti and others, 2002) have been conducted under laboratory conditions.

In recent years, initial research projects have been carried out using TLS to monitor spatial changes of the snow depth (Bauer and Paar, 2004; Prokop, 2005; Jörg and others, 2006). Monitoring small variations caused by snowdrift or melting over a winter period provides a basis for avalanche forecasting. TLS methodology enables monitoring activities to be performed several times a day, so physically based snowpack models can be evaluated based on precise data (Prokop and Teufelsbauer, 2007).

However, detailed conclusions about the possibilities and limitations of TLS under rough alpine weather conditions require a comparison with traditional methods. This evaluation of TLS was performed within this research project based on tachymetry (the most highly developed measuring technology) and snow probing (sticking a scaled pole vertically into the snowpack at locations of interest by hand and noting the snow depth). Ultrasonic snow-depth measurements, the standard method for measuring snow depth at single points, were also employed to obtain comparative data. Tachymeter datasets were used as reference models.

\section{MEASUREMENTS}

\section{Instrumentation}

Reflectance of the snowpack surface depends on laser wavelength and grain size in the surface layer of the snowpack. In order to achieve comparable results, the 
Table 1. Technical parameters of the instruments used

\begin{tabular}{|c|c|c|c|}
\hline Criterion & Unit & TLS & Tachymeter \\
\hline Instrument used & & Riegl LPM-i800ha & Leica TCRP1201 \\
\hline Wavelength & $\mathrm{nm}$ & 900 & 670 reflectorless \\
\hline Maximal range & $\mathrm{m}$ & 800 & 500 \\
\hline Range accuracy $1 \sigma$ & $\mathrm{mm}+\mathrm{ppm}$ & $15+20$ & $3+2$ \\
\hline Angular accuracy $1 \sigma$ & $\circ$ & 0.009 & 0.00027 \\
\hline \multicolumn{4}{|l|}{ Beam size $(V \times H)$} \\
\hline at $100 \mathrm{~m}$ & $\mathrm{~mm}$ & $130 \times 130$ & $12 \times 40$ \\
\hline at $500 \mathrm{~m}$ & $\mathrm{~mm}$ & $650 \times 650$ & $60 \times 200$ \\
\hline Scan speed & pts s $^{-1}$ & 1000 & $1 / 6$ \\
\hline Inclination sensor & & no & yes \\
\hline CCD* camera & & yes & no \\
\hline Approx. weight (excluding tripod) & $\mathrm{kg}$ & 15 & 5.8 \\
\hline in terms of details & & good & marginal \\
\hline in terms of changes in object space & & moderate & marginal \\
\hline
\end{tabular}

*Charge-coupled device.

duration of a scan was limited to 2 hours. Thereby, it was possible to limit changes in meteorological conditions and resultant snowpack metamorphosis that might interfere with comparison of the different measurement methods. The obtainable resolution of the target is also determined by the technical capability of the device. Higher-resolution laser measurements provide better comparison capabilities in terms of smaller interpolation errors, when building a digital surface model. Typically, measured areas of interest for snow and avalanche research are difficult to reach and are at least $500 \mathrm{~m}$ in length. The scanning range of the device must measure up to this range in order to be considered a viable measurement option.

In accordance with the above-mentioned guidelines, the Riegl LPM-i800HA long-range laser scanner was chosen. The laser wavelength of $0.9 \mu \mathrm{m}$ allows distances up to $800 \mathrm{~m}$ to be observed with a reflectance of $80 \%$. The laser beam reflectance is dependent on snow grain sizes (Painter and Dozier, 2004) and snow wetness (Prokop, 2005). In previous studies, it was not possible to detect infiltration of the laser beam into the snowpack at this wavelength (Prokop, 2005). The scanning speed of $1000 \mathrm{~Hz}$ made it possible to scan the chosen test areas within 2 hours, when using the highest resolution of $30 \mathrm{~mm}$ at a target range of $100 \mathrm{~m}$.

Without the use of a retro-reflector, the Riegl LPMi800HA calculates the distance to the surface based on the time-of-flight method. For Riegl instruments, the laser signal is pulsed, i.e. the time of flight is evaluated by measuring the time interval between transmitting a short pulse and receiving its backscatter.

Tachymetry measurements were observed using Leica TCRP1201 systems. Some measurements were taken towards retro-reflective targets (three-dimensional (3-D) point accuracy below $1 \sigma=5 \mathrm{~mm}$ ), but most of the data were collected in a reflectorless mode, which typically achieves 3-D point accuracies below $10 \mathrm{~mm}$.

In comparing TLS with the tachymeter, Table 1 outlines the most important technical parameters of the instruments used. These data are only valid for the instruments used in the present study.

\section{METHODOLOGY Data acquisition}

To analyze the different methods, several measurements of the snowpack surface were performed and snow-depth differences were compared. The snow depth was determined at different times of day between 12 February and 9 March 2007. This period was chosen in order to avoid the scanning of wet snow surfaces, which would reduce the laser intensity depending on the range of the target and on the angle of incidence (Prokop, 2005).

Three subareas of investigation were chosen within the SLF test site at Weissfluhjoch, Davos, Switzerland ( 2540 ma.s.l.; Fig. 1). Subarea 1 was located $\sim 20-80 \mathrm{~m}$ from the scanner position, and two ultrasonic snow-depth sensors and a snow-depth gauge were used for the comparison. Subarea 2 was located $\sim 180-310 \mathrm{~m}$ from the scanner position. Most of the evaluation was carried out here, with 95 bamboo sticks inserted into the snowpack as markers to ensure the accuracy of measurement positions. All three measurement methods - probing, tachymetry and laser measurement - were carried out at these 95 points, providing the dataset for analysis. In addition, low-resolution tachymetry raster scans of subarea 2 allowed comparisons to laser scans. Subarea 3 was located $\sim 305-450 \mathrm{~m}$ from the scanner position. Nine scaled poles were placed into the test site, while changes in snow depth were estimated using binoculars. Later observations were then used for comparison with the long-range laser scanner.

Changes in snow depth observed by the different methods were compared. Absolute-depth values were also compared between TLS and the tachymetry survey. To compare these methods and the different measurements produced, georeferencing of data is required. Georeferencing, or the socalled registration of TLS, is the process of transforming a point cloud, in the local scanner coordinate system, into a reference coordinate system. The transformation is described by three translational and three rotational parameters, requiring a rigid geodetic network encompassing several tie points (reference points). This becomes crucial for long- 


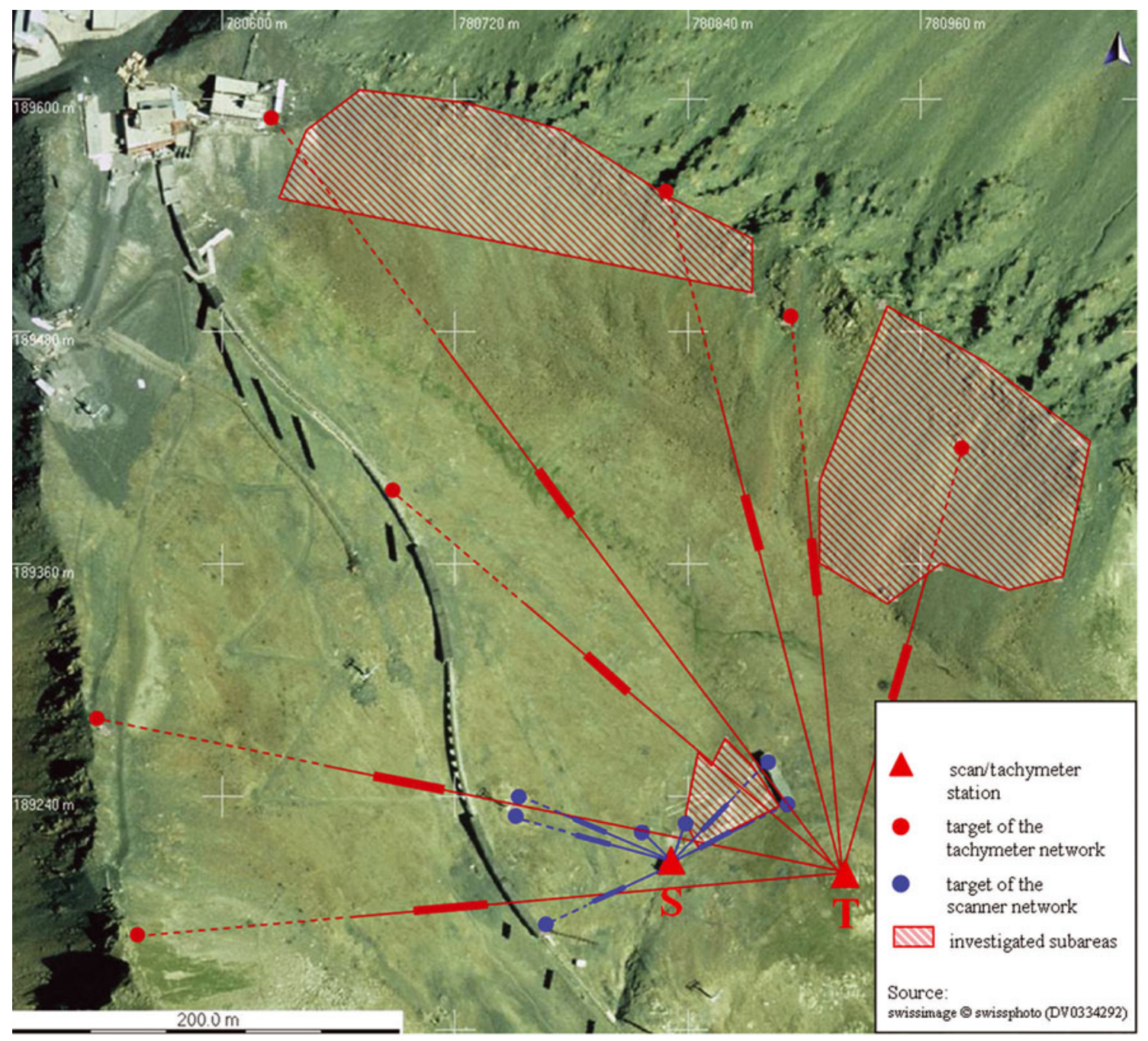

Fig. 1. Map of test site location.

term observation, where the reference system needs to be stable. Requirements of the network included:

1. stability for long-term use;

2. sufficient spatial distribution to ensure a sufficient registration;

3. sufficient tie points;

4. single-point accuracy of tie-point coordinates;

5. reliability of tie-point coordinates.

The geodetic network was observed from three positions, which had also been determined with the differential global positioning system (GPS). The set-up ensured increased redundancy and, hence, the reliability of the single-tie-point coordinates. However, the tie points were used to register all scan positions in the same reference system. Assuming diminished accuracies or probable systematic errors during the registration process may result in large displacements or misalignment between compared datasets.

\section{Post-processing}

Measurements obtained from manual probing are taken in the vertical direction. For comparative purposes, the snow depth needs to be similarly extracted from the scans and tachymetry data. For this reason, digital surface models
(DSMs) of the snow cover were produced from the scanned point cloud. Distances of points measured by tachymetry were also computed vertically to the snow-cover DSMs. In order to provide comparable DSMs, the following three significant data post-processing steps were executed:

1. data quality check;

2. data filtering;

3. triangulation of the point clouds to surfaces.

Data quality was ensured by controlling the registration accuracy. Based on experience and our requirements, the registration of the specific scan had to be within a 3-D accuracy of $1 \sigma=30 \mathrm{~mm}$.

Since the registration accuracy does not always expose misalignment of the scan, all scans were manually reviewed by the operator with respect to a reference scan. Misaligned scans could be easily detected and eventually removed for further processing. A total of $23 \%$ of all scans had to be removed due to data gaps (caused by the weather) or because they did not meet the above-mentioned requirements.

To produce DSMs of the snow surface, any data above the surface that did not belong to the snowpack were removed (e.g. data acquired using the bamboo sticks in subarea 2 or ultrasonic sensors in subarea 1). A simple Geographical Information System (GIS) application was used to filter the data. 


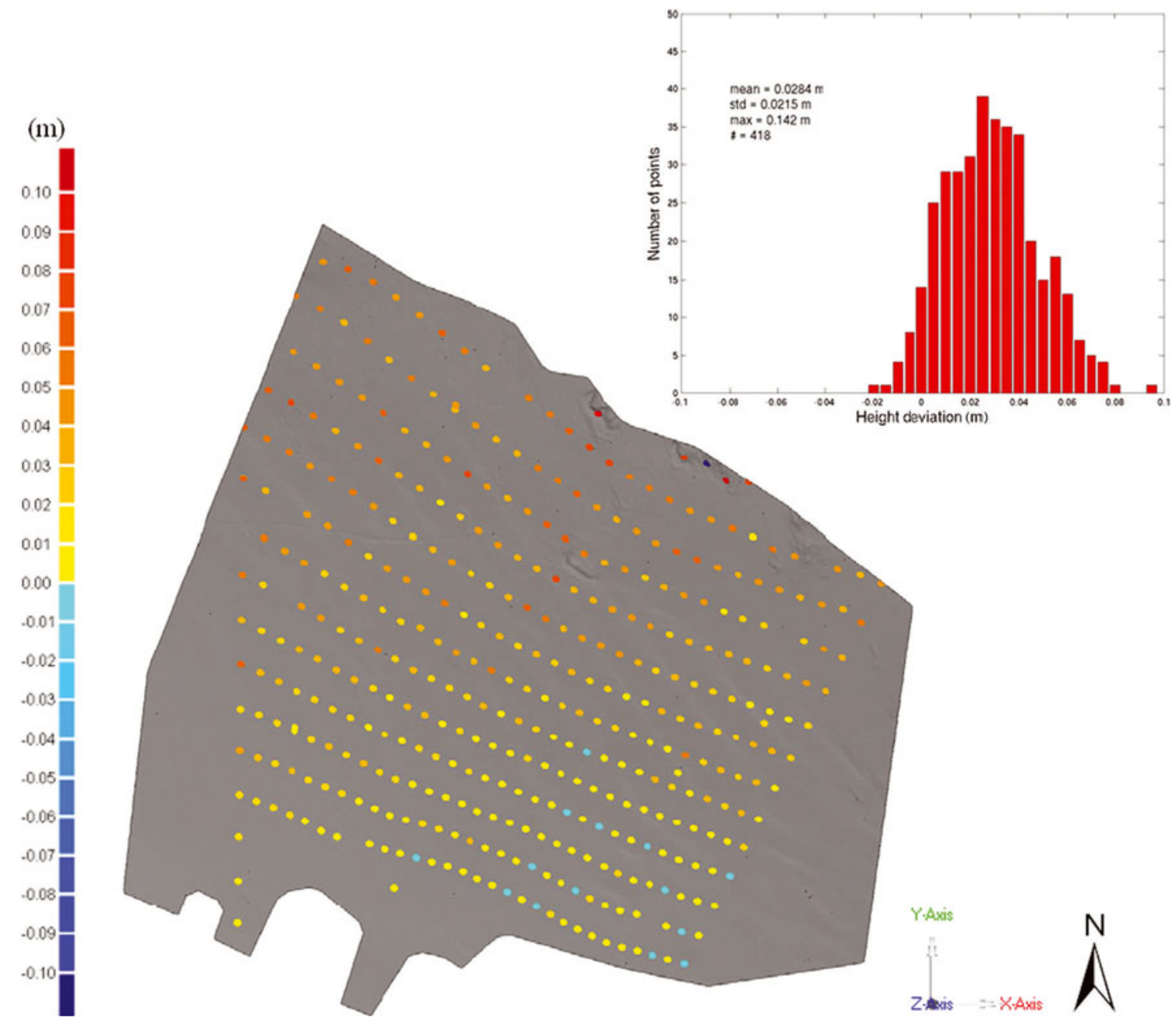

Fig. 2. The triangulated scan captured by the TLS, used as a reference while the tachymeter raster is set as a test. Single-point depth deviation is shown in the histogram (scale: meters).

The main goal was to prevent manipulation of point data on the snow surface, while removing, as far as possible, all data that did not belong to it. This method is comparable to a 2.5dimensional (2.5-D) filter, which is used to filter airborne scanning data and, in particular, to remove vegetation and buildings in the creation of digital terrain models, so that only one point (usually the lowest point) remains for the same $x, y$ coordinates (Kobler and others, 2007).

Using the filtered data, it was possible to generate DSMs by triangulation. The triangulation process was executed within the scanner software RiPROFILE (http://www.riegl. com). Further processing steps were performed in Geomagic Qualify version 8 (http://www.geomagic.com), a software package often used in reverse engineering, quality inspection and analysis applications. It offers 3-D comparisons, as well as a 3-D visualization, of surfaces and point clouds. The software was used to obtain fast visualizations of scan comparisons of depth offsets. It also enables the user to generate several quality reports. Compared to ArcGIS and other GIS software packages, one of its benefits is that the comparison algorithm works three-dimensionally. However, RiPROFILE and Geomagic lack transparent information about the algorithms used to compute triangulation and comparisons. In other words, the software does not give the user precise information on how values have been derived. To back up the conclusion drawn from these comparisons, a
MATLAB ${ }^{\mathrm{TM}}$ routine was written. Thereby, the triangulation of the point data was generated using Delauney algorithms, whereas the difference in depth was computed on the $z$ axis from point to surface.

\section{RESULTS AND DISCUSSION}

\section{Comparison of TLS, tachymetry and probing (subarea 2)}

The comparison of TLS, tachymetry and manual probing was based on data measured in subarea 2. This subarea was simultaneously scanned by TLS and tachymeter, and absolute depth values were compared. The tachymeter was placed slightly closer to the subarea than the TLS. Both positions are depicted in Figure 1. The tachymeter raster encompasses 420 points and has a constant angular step width of $1.8^{\circ}$, so the raster size varies within the subarea. The raster has a minimum size of $3 \mathrm{~m}$ (at the bottom of the area) and increases in larger ranges up to $10 \mathrm{~m}$. The scan resolution of the TLS was set to $0.018^{\circ}$, resulting in a minimum raster size of $0.06 \mathrm{~m}$ in the southern part and $0.1 \mathrm{~m}$ in the northern part of the subarea.

Figure 2 shows the comparison, in which the triangulated TLS surface acts as a reference, and the points observed by the tachymeter are set as a test. Depth deviations show a 

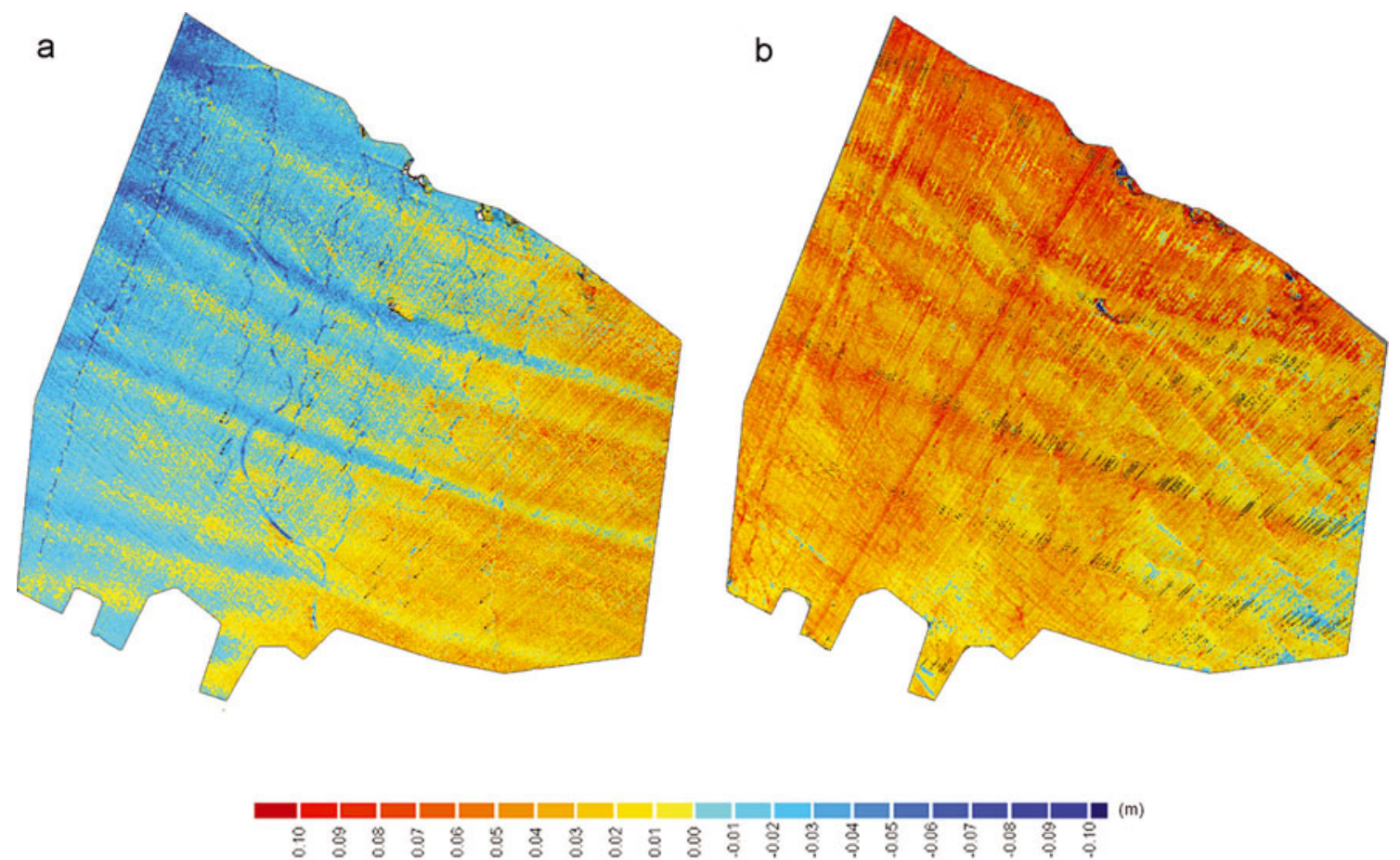

Fig. 3. The reproducibility test was executed with two scans, which have been registered individually. The scans were taken during the same day with a time delay of 3.5 hours ((a) and (b) show different cases on different days). Each case consists of two scans: a scan taken at $0900 \mathrm{~h}$ acts as a reference scan, whereas a scan at $1315 \mathrm{~h}$ is taken as a test scan (scale: meters).

mean of $2.8 \mathrm{~cm}$, with a standard deviation of $2.2 \mathrm{~cm}$. The points captured by the tachymeter generally lie slightly above the triangulated scan. In comparing these two datasets, a specific type of systematic error is visible. Despite some outliers, the tachymeter points lie closest to the scan (some even below it) in the southeastern part of the subarea. Moving diagonally northwestwards, an increasing depth deviation is visible. Since the gradient of these increasing depth deviations points to the tachymeter station, the following hypotheses could be supported:

Different distances and angles of incidence affect the accuracy of tachymeter and laser data.

Problems occur when measuring reflectorless distances on snow using the tachymeter.

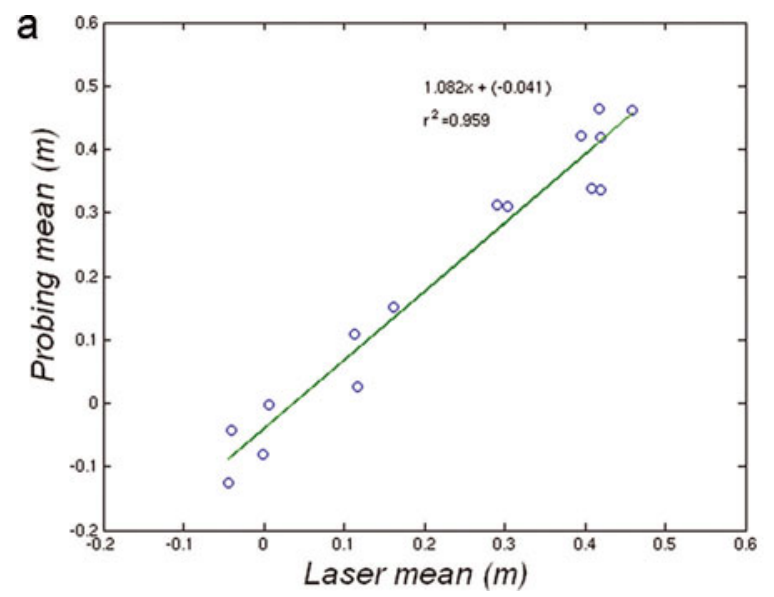

The TLS is misaligned with respect to the reference system, which would also cause a misalignment against the tachymeter (see comparison in Fig. 3a).

These hypotheses were also arrived at by analyzing the 12 datasets, which were used to compare TLS with tachymetry. The mean depth deviation ranged in a bandwidth of $\pm 8 \mathrm{~cm}$, while the standard deviation was constantly approximately $1 \sigma=2 \mathrm{~cm}$. In most comparisons, there is a systematic error mainly caused by misalignment of the TLS with respect to the reference system. The results of the scanner misalignment are clearly shown in a reproducibility test. Reproducibility is defined as the closeness of two results of measurements based on the same object carried out under changed measurement conditions. In this case, the changed conditions included

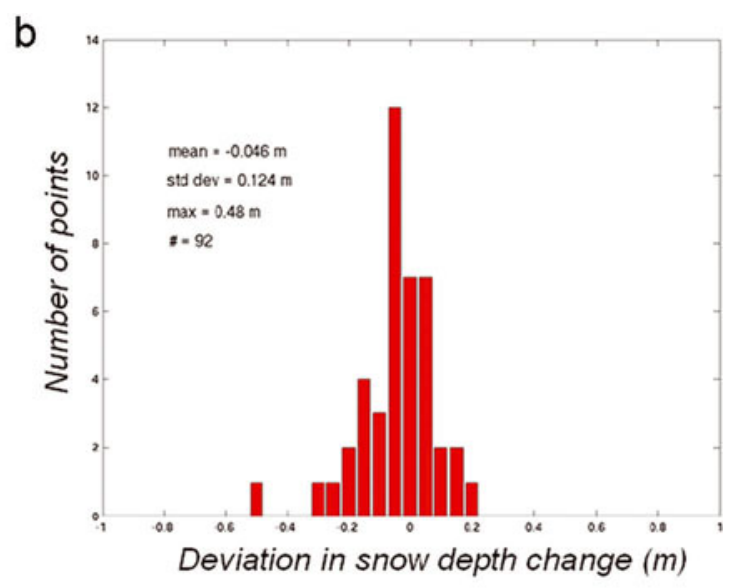

Fig. 4. Comparison of manual probing with TLS measurements. (a) One laser scan per day was compared with manual probing. (b) Typical behaviour of the manual probing error in comparison to TLS. Mean deviation is $0.046 \mathrm{~m}$; standard deviation is $0.124 \mathrm{~m}$. 


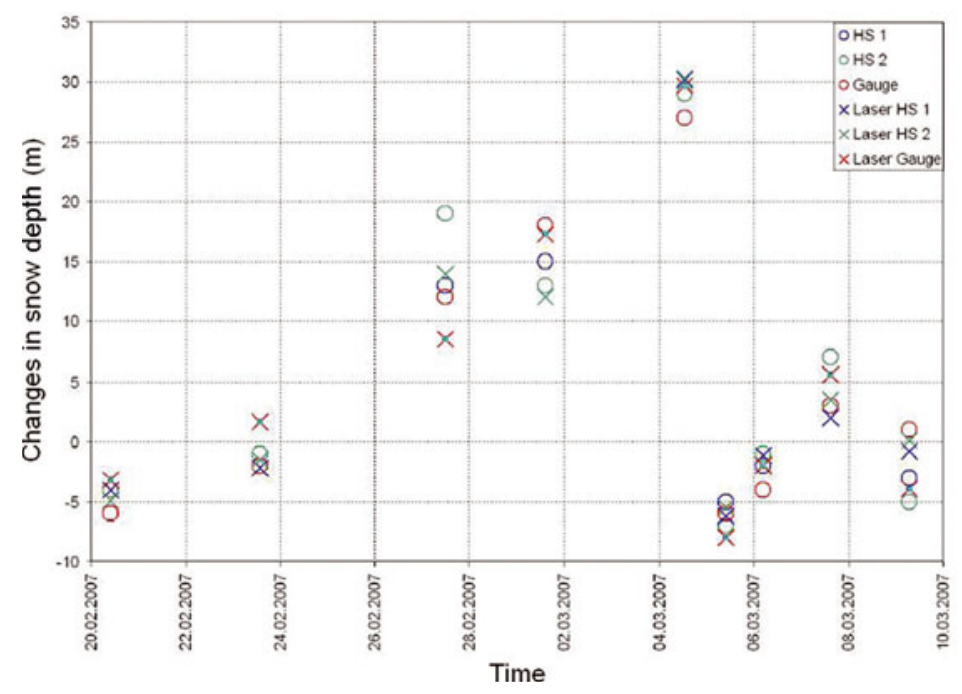

Fig. 5. Comparison of laser and ultrasonic measurements by plotting snow-depth changes against time (dd.mm.yyyy).

differences in scanner set-up, meteorology, time of day and separate registration. Figure 3 a shows a tilt axis vertically orientated in the middle of the scan. This is caused by misalignment of one of the scans, which results in a depth deviation of $1 \sigma=4 \mathrm{~cm}$. With increasing distance from the tilt axis, depth deviation also increases. This outcome was confirmed by the reproducibility test in subarea 3 . The nine other reproducibility tests showed similar results. Figure $3 \mathrm{~b}$ shows offsets of up to $8 \mathrm{~cm}$ between the scans, which are assumed to be caused by misalignment of the scanner. Deviations between TLS and tachymetry are in the same range as in the reproducibility test.

A comparison of 15 manual ground-probing datasets with TLS was executed at the 95 bamboo sticks recording changes in snow depth. The mean snow-depth changes correlated well between different methods, as shown in Figure 4a. The results must be interpreted according to the reproducibility test described above. The mean standard deviations, however, are significantly over $1 \sigma=10 \mathrm{~cm}$ (cf. histograms in Figs 2 and 4b).

\section{Comparison of TLS and ultrasonic measurements}

A comparison of TLS and ultrasonic measurements was conducted using data measured in subarea 1. A snow-depth gauge reading was also used. Snow-depth variations were computed based on scans performed on different days over a specific time period, carried out in accordance with the methodology explained above. Thereafter, these variations were compared with the snow depth measured by the ultrasonic sensors and the gauge. Figure 5 shows the changes in snow depth with time that were measured using the different methods. The results show similarities with the comparison between tachymetry and TLS. The mean deviation of snow-depth changes was $1 \sigma=5 \mathrm{~cm}$. Figure 5 also shows an error due to the large angle of incidence of the laser beam, which occurs even at small distances to the target. Nevertheless, the trend of gaining or losing snow depth was clearly determined by TLS.

The data acquired in subarea 3 from a visual reading of scaled poles could not be used as a quality check, as the accuracy of the visual read-off by binoculars was not satisfactory.

\section{CONCLUSIONS}

For the first time, a comparative study has given a detailed quantification of the accuracy with which TLS, tachymetry and manual probing determine relative snow depths on slopes. Knowledge of the spatial and temporal distribution of snow depth is a key parameter in the assessment of avalanche hazards. The possibilities of measuring the spatial snow-depth distribution on slopes using TLS technology have been shown in previous studies, but a detailed investigation of accuracy limitations has been missing until this project. To deliver reliable conclusions, it was necessary to measure under real mountainous conditions, so guidelines can be drawn for potential new users.

The results clearly showed that TLS is a powerful technology for measuring the spatial snow-depth distribution quickly (scanning time $<2$ hours) and with a high point resolution. The accuracy of the laser measurement showed a mean deviation to the tachymetry survey of maximum values of $\pm 8 \mathrm{~cm}$ and a mean value of $4.5 \mathrm{~cm}$, whereas the standard deviation was approximately $1 \sigma=2 \mathrm{~cm}$ at distances up to $300 \mathrm{~m}$. On the one hand, the systematic error detected is caused by misalignment during registration. On the other hand, external forces (e.g. wind or solar radiation) influenced the laser device, which had been mounted on a tripod. When using an entirely fixed mounting for the laser device and a protection against external forces, the standard deviation error is likely to be reduced. However, it is not possible to determine small, timedependent changes in snow depth using this particular laser device and the same methodology due to:

1. errors in the registration process (according standard deviations of approximately $2 \mathrm{~cm}$ ),

2. beam diameter $(13 \mathrm{~cm}$ at $100 \mathrm{~m})$, which is linearly increasing with distance, and

3. resolution of the point cloud data $(3 \mathrm{~cm}$ at $100 \mathrm{~m}$ from the scanner position; this value increases with increasing angles of incidence).

The laser measurement has major advantages over manual probing, which, as well as being a time-consuming and 
potentially dangerous method, is one with which limited accuracy is achievable, with a mean standard deviation of $>10 \mathrm{~cm}$. No conclusion can be drawn about the accuracy of the tachymetry survey. Tachymetry was used as the reference model due to the long history and proven accuracy of the technology. As a time-consuming method with low reachable point densities and limitations in the possible measured ranges to the target, tachymetry appears to be unsuitable for measuring spatial dimensions of snowpacks.

TLS was the most efficient method for measuring the spatial distribution of snow depths. Loading of slopes through new snow and wind, as well as settling of old snow, can be detected within the above-mentioned accuracy limitations. TLS can be used for numerous applications in snow and avalanche research (e.g. evaluating physical snowdrift or snowpack models). It will also be very useful for dynamic avalanche research to determine the snow mass displacement after avalanche events. It is therefore necessary to perform scans prior to and after an event, which can be executed experimentally. Scans from the avalanche release zone, runout zone and an avalanche track for estimating snow entrainment will contribute significantly to improving the parameters of dynamic avalanche models.

\section{ACKNOWLEDGEMENTS}

This work was partially funded by the Swiss National Science Foundation and the Swiss Federal Office of the Environment. We thank P. Thee for two tachymetry measurements. M. Rub and M. Stocker thank H. Ingensand, head of the group for Metrology and Engineering Geodesy at ETH Zürich, for agreeing to this international research project. We also thank H.M. Zogg for support during the project, and the anonymous reviewers whose comments substantially helped to improve the paper.

\section{REFERENCES}

Bauer, A. and G. Paar. 2004. Monitoring von Schneehöhen mittels terrestrischem Laserscanner zur Risikoanalyse von Lawinen. In Ingenieurvermessung 2004, 14th International Conference on Engineering Surveying, 15-19 March 2004, Zürich, Switzerland. Proceedings. Zürich, ETH Zürich.

Boehler, W. and A. Marbs. 2002. 3D scanning instruments. In Boehler, W., ed. Proceedings of the CIPA WG 6 International Workshop on Scanning for Cultural Heritage Recording, 1-2 September 2002, Corfu, Greece. International Society for Photogrammetry and Remote Sensing/International Committee for Documentation of Cultural Heritage.
Corripio, J.G., Y. Durand, G. Guyomarc'h, L. Mérindol, D. Lecorps and P. Pugliése. 2004. Land-based remote sensing of snow for the validation of a snow transport model. Cold Reg. Sci. Technol., 39(2-3), 93-104.

Hopkinson, C. and 10 others. 2001. Mapping the spatial distribution of snowpack depth beneath a variable forest canopy using airborne laser altimetry. In Hardy, J. and S. Frankenstein, eds. Proceedings of the 58th Eastern Snow Conference, 17-19 May 2001, Ottawa, Ontario, Canada. Hanover, NH, US Army Cold Regions Research and Engineering Laboratory, 253-264.

Ingensand, H. 2006. Methodological aspects in terrestrial laserscanning technology. In Kahmen, H. and A. Chrzanowski, eds. Proceedings of the 3rd IAG Symposium of Geodesy for Geotechnical and Structural Engineering and 12th FIG Symposium on Deformation Measurements, 22-24 May 2006, Baden, Austria. Vienna, International Association of Geodesy/International Federation of Surveyors. CD-ROM

Jörg, P., R. Fromm, R. Sailer and A. Schaffhauser. 2006. Measuring snow depth with a terrestrial laser ranging system. In Proceedings of the International Snow Science Workshop, 1-6 October 2006, Telluride, Colorado. Telluride, CO, International Snow Science Workshop, 452-460. CD-ROM.

Kobler, A., N. Pfeifer, P. Ogrinc, L. Todorovski, K. Oštir and S. Džeroski. 2007. Repetitive interpolation: a robust algorithm for DTM generation from Aerial Laser Scanner Data in forested terrain. Remote Sens. Environ., 108(1), 9-23.

Lichti, D.D., S.J. Gordon, S.J. Stewart, M.P. Franke and M. Tsakiri. 2002. Comparison of digital photogrammetry and laser scanning. In Boehler, W., ed. Proceedings of the CIPA WG 6 International Workshop on Scanning for Cultural Heritage Recording, 1-2 September 2002, Corfu, Greece. International Society for Photogrammetry and Remote Sensing/International Committee for Documentation of Cultural Heritage, 39-44.

Painter, T.H. and J. Dozier. 2004. The effect of anisotropic reflectance on imaging spectroscopy of snow properties. Remote Sens. Environ., 89(4), 409-422.

Prokop, A. 2005. Hangbezogene Ermittlung der flächigen Schneehöhenverteilung mittels Laserscanners. Wildbach- und Lawinenverb. 154.

Prokop, A. and H. Teufelsbauer. 2007. Die flächige Schneehöhenmessung mittels terrestrischer Laserscanner als Grundlage für Schneedeckenmodellieurngen. In Bergmeister, K., M. Fiebig, F. Florineth and W. Wu, eds. Proc. 1. Departmentkongress zu Bautechnik und Naturgefahren, 10-11 Mai 2007, Wien. Vienna, Ernst \& Sohn Verlag, 44-49.

Rosenthal, W. and J. Dozier. 1996. Automated mapping of montane snow cover at subpixel resolution from the Landsat thematic mapper. Water Resour. Res., 32(1), 115-130.

Sovilla, B., P. Burlando and P. Bartelt. 2006. Field experiments and numerical modelling of mass entrainment in snow avalanches. J. Geophys. Res., 111(F3), F03007. (10.1029/2005JF000391.)

Yankielun, N., W. Rosenthal and R.E. Davis. 2004. Alpine snow depth measurements from aerial FMCW radar. Cold Reg. Sci. Technol., 40(1-2), 123-134. 